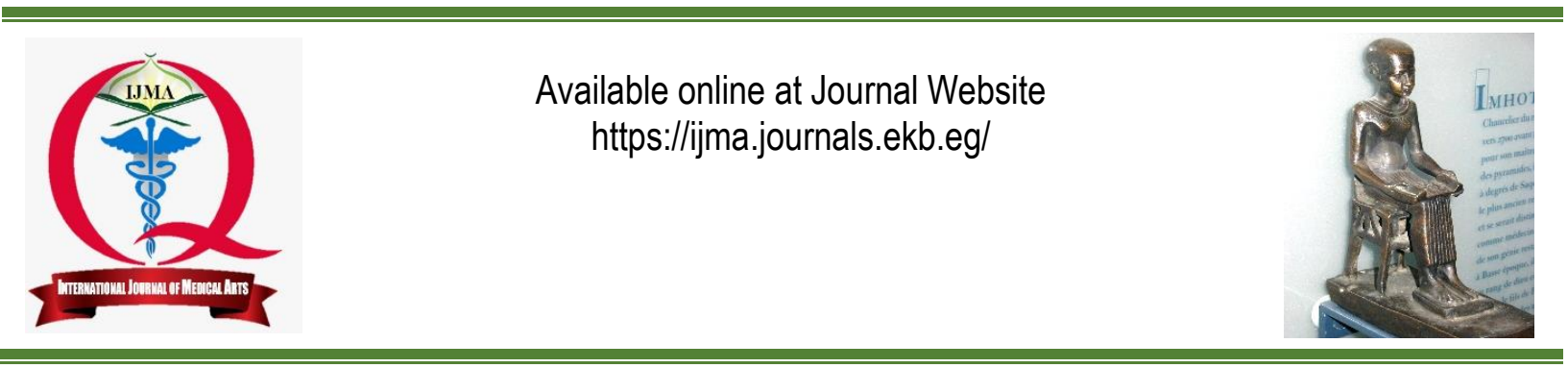

Original article

\title{
Surgical Field Visibility during Functional Endoscopic Sinus Surgery: Esmolol-induced Hypotensive Anesthesia versus Hypotensive Total Intravenous Anesthesia
}

\author{
Mostafa E.M. Ahmed ${ }^{\mathbf{a}} ;$ Mahmoud M. Elsayeda ${ }^{\mathbf{a}}$ Nabil Abdelghany Sarhan ${ }^{\mathbf{b}}$; Mohamed Ahmed Fathallah ${ }^{\mathbf{b}}$ \\ Department of Anesthesiology and Intensive care, Faculty of Medicine, Al-Azhar University, Egypt [a]; Alhammadi Hospital, \\ Kingdom of Saudi Arabia [KSA] \\ Department of Otorhinolaryngology, Damietta Faculty of Medicine, Al-Azhar University, Egypt [b]; Alhammadi Hospital, Kingdom \\ of Saudi Arabia [KSA]
}

Corresponding author: Nabil Abdelghany Sarhan

Email: nabelent@yahoo.com

Received at: August 20, 2019; Revised At: September 29, 2019.

Accepted at: September 29, 2019; Available online at: September 29, 2019

DOI: 10.21608/ijma.2019.16039.1023

\begin{abstract}
Background: Functional endoscopic sinus surgery is widely practiced during daily otorhinolaryngology practice. It usually done under low blood pressure. However, the ideal hypotensive drug or technique is yet not well established.

Aim of the work: To evaluate outcome of functional endoscopic sinus surgery under esmolol-induced hypotensive anesthesia [EHA] versus hypotensive total intravenous anesthesia [H-TIVA].

Patients \& Methods: 72 patients were randomly divided into two groups; Group A: H-TIVA and Group B [EHA]. After induction of anesthesia, remifentanil/ propofol and esmolol infusions were adjusted to maintain mean arterial pressure at 60-70 $\mathrm{mmHg}$. After completion of surgical procedure, esmolol infusion was stopped, while remifentanil/propofol infusions were adjusted to allow restoration of blood pressure. Operative field bleeding and visibility were graded using Fromme scale. Primary outcome is the efficacy of EHA to minimize intraoperative bleeding to an extent that allows satisfactory completion of surgery.

Results: Esmolol bolus significantly attenuated pressor reflexes to induction and intubation than induction by remifentanil. Intraoperative [1O] heart rate and MAP measures were significantly lower with EHA. At 10-minures after infusion stoppage, patients of group B still had significantly lower HR and MAP, while at 10-min later, the difference was nonsignificant. HA minimized 10 blood loss down to no to slight bleeding in $16.7 \%$ and $55.5 \%$ of studied patients and improved field visibility to satisfactory-to-good levels in $51.4 \%$ and $43.1 \%$ of surgeries, respectively. Moreover, EHA provided better field visibility, so allowed significant reduction of operative time than with TIVA.

Conclusion: Hypotensive anesthesia is safe and appropriate modality for FESS and improves surgical and clinical outcome. Both esmolol and remifentanil provided satisfactory results. Esmolol is superior to remifentanil.
\end{abstract}

Keywords: Esmolol hypotensive anesthesia; Hypotensive total intravenous anesthesia; Intraoperative bleeding; Operative field visibility.

This is an open access article under the Creative Commons license [CC BY] [https://creativecommons.org/licenses/by/2.0/]

Please cite this article as: Ahmed MEM, Elsayed MM, Sarhan NA, Fathallah MA. Surgical Field Visibility during Functional Endoscopic Sinus Surgery: Esmolol-induced Hypotensive Anesthesia versus Hypotensive Total Intravenous Anesthesia. IJMA 2019; 1[2]: 110118. 


\section{INTRODUCTION}

Chronic rhinosinusitis [CRS] is a broad clinical syndrome associated with mucosal inflammation[1] and affects about $14.2 \%$ of adult population[2]. Sinonasal and sleep-related symptoms affect physical and emotional aspects of daily function [3] with subsequent poor quality of life ${ }^{[4]}$ that promotes those patients to seek sinus surgery[4].

Functional endoscopic sinus surgery [FESS] is a minimally-invasive surgical technique for CRS especially in CRS with polyps ${ }^{[5]}$ and became the well-established approach for CRS refractory to medical management[6]. Advantages of FESS include recovery of antral mucosa and improvement of mucociliary clearance with improved ventilation and drainage [7]. Additionally, FESS induced marvelous symptomatic outcome in the form of significant decrease of symptoms' scores ${ }^{[8]}$.

Optimal surgical field visibility is the most vital aspect of FESS[9] as small bleeding areas can reduce surgical field visibility and result in destruction of surrounding structures ${ }^{[10]}$. This invariably requires induced hypotensive anesthesia $[\mathrm{HA}]$ to facilitate surgical dissection and decrease operative time[9].

Wide range of pharmacological agents were tried to achieve IHA during FESS; dexmedetomidine provides better hemodynamic stability and operative field visibility [11], clonidine was found to be effective in achieving $\mathrm{IHA}^{[12]}$ and lidocaine provided better surgical field clarityl[3]. Remifentanil anesthesia with propofol or desflurane resulted in good field visibility, with no clinical differences between propofol and desflurane ${ }^{[14]}$.

Esmolol is a unique cardioselective $\beta 1$ adrenergic receptor antagonist with strongly $\beta 1$ selective activity at conventional clinical doses ${ }^{[15]}$. It is highly effective in prevention of tachycardia secondary to sympathoadrenal system activation during anesthesia induction[16,17]. Low dose of esmolol might induce vasodilator effect resulting in changes in the resistance of vessels, thus provides perioperative cardiac safety[18], stable intraoperative hemodynamics and protection against surgical stress response ${ }^{[19]}$.

Esmolol is ultrashort acting drug, metabolized by red blood cell esterases resulting in a 9-minute half-life[20]. Its dosing regimen must vary with patient's status, clinical situation, concomitant medications, desired result and duration of surgery [17]. Esmolol administration may be associated with increased risk of hypotension, so continuous monitoring of patients receiving esmolol is mandatory[21].

\section{AIM OF THE WORK}

The study aimed to evaluate outcome of FESS under esmolol-induced hypotensive anesthesia $[\mathrm{EHA}]$ versus hypotensive total intravenous anesthesia [H-TIVA].

\section{PATIENTS AND METHODS}

Setting: Departments of Anesthesia and Otorhinolaryngology, Alhammadi Hospital, Kingdom of Saudi Arabia [KSA]

Design: Prospective comparative clinical trial

The current study was conducted since June 2017 till April 2019. The study protocol was approved by the Local Ethical Committee of Alhammadi Hospital, Kingdom of Saudi Arabia, and enrolled patients signed an informed written consent for study participation, receiving the assigned anesthetic procedure and to undertake surgical treatment of their sinus disease. All patients presenting to outpatient clinic of otorhinolaryngology with symptoms suggestive of chronic rhinosinusitis [CRS] were eligible for evaluation. CRS was diagnosed according to criteria defined by the Rhinosinusitis Task Force ${ }^{[22]}$ and patients have $\geq 2$ major or one major plus $\geq 2$ minor factors for $\geq 12$ weeks despite of medical therapy for 4 weeks were enrolled in the study. Patients with acute sinus disease, ASA grade III or IV, cardiovascular disease, hypertension, bleeding diathesis and maintained on aspirin or other medications affecting coagulation system and patients with kidney or liver dysfunctions, as well as anemia [Hb<10 g/dl] were excluded from the study.

All patients underwent clinical examination including endoscopic evaluation of the extent of sinus disease using Lund \& Kennedy [23] endoscopic grading to assess nasal mucosa edema, presence of secretion and presence of polyps; each parameter was scored by 0-2. Assessment was performed bilaterally and total score equals the sum of points obtained in both sides to give a score range of $0-12$. Then, all patients underwent CT scanning of paranasal sinuses at coronal and axial plans with continuous sections of 2.0 and $3.0 \mathrm{~mm}$ thickness. CT scans were assessed according to 
Lund-Mackay ${ }^{[24]}$ scale. Each paranasal sinus was graded from 0 to 2 depending on the level of opacification and the ostiomeatal complex was scored by 0 [no obstruction] or 2 [obstructed]. Assessment was conducted bilaterally for a total score range of 0-24 points, and the highest value corresponded to greater severity of the disease.

Randomization \& grouping: Randomization was conducted using sealed envelopes containing cards carrying the group label and prepared by an assistant who was blinded about target for each group and envelops were chosen by patient him/herself. Patients fulfilling the inclusion criteria were randomly allocated into two equal groups according to the applied anesthetic procedure as Group A which included patients received TIVAinduced hypotensive anesthesia and Group B which included patients received esmolol-induced hypotensive anesthesia.

Anesthetic procedure: All patients were premedicated with midazolam [0.05 mg/kg], 2 minutes before induction of anesthesia. For patients of Group A, anesthesia was induced by a bolus of remifentanil $[1 \mu \mathrm{g} / \mathrm{kg}$ ] followed by propofol [1-2 $\mathrm{mg} / \mathrm{kg}$ ] and rocuronium $0.6 \mathrm{mg} / \mathrm{kg}$ to facilitate tracheal intubation. Anesthesia was maintained by slow remifentanil infusion [2 $\mathrm{mg}$ in $40 \mathrm{cc}$ of physiological saline] in addition to $50 \mathrm{cc}$ of propofol infusion with rate was adapted according to hemodynamic responses, in order to maintain mean arterial blood pressure [MAP] values in the range of 60-70 mmHg. For Patients of Group B, esmolol was given as an intravenous bolus dose of 0.5 $\mathrm{mg} / \mathrm{kg}$ diluted in $10 \mathrm{ml}$ of $0.9 \%$ normal saline and then anesthesia was induced using propofol 2 $\mathrm{mg} / \mathrm{kg}$, fentanyl $1-2 \mathrm{ug} / \mathrm{kg}$, and rocuronium 0.6 $\mathrm{mg} / \mathrm{kg}$ to facilitate tracheal intubation. Then, esmolol infusion was started at rate of 0.05-0.3 $\mathrm{mg} / \mathrm{kg} / \mathrm{min}$ to maintain MAP of $60-70 \mathrm{mmHg}$ until completion of surgery. Balanced anesthesia was continued with sevoflurane, fentanyl and rocuronium adapted to the patient's physiological reaction to surgical stimuli. For patients of both groups, the lungs were ventilated with $100 \% \mathrm{O} 2$ in air using a semi-closed circle system. Ventilation was controlled with a tidal volume of 6-8 $\mathrm{ml} / \mathrm{kg}$, and the ventilatory rate was adjusted to maintain an end-tidal carbon dioxide [paCO2] of 32-35 $\mathrm{mmHg}$. After completion of surgical procedure, esmolol infusion was stopped and remifentanil/propofol infusions were adjusted to allow restoration of blood pressure so that perfect hemostasis could be achieved.

Operative procedure: Immediately after tracheal intubation, middle meatus cavity was packed under endoscopic guidance by adrenaline $[1: 100,000]$ soaked pledges to obtain maximum contraction at sinus mucosa to allow better visualization. Pledges were removed after 5-min and mucosa of uncinate process was injected by 1 $1.5 \mathrm{ml}$ of xylocaine [1\%] with adrenaline $[1: 100,000]$. Xylocaine injection was performed at level of the head of the middle turbinate and the inferior part of the bulla to block branches of the anterior ethmoidal nerve. Prior to initiation of the procedure, operative table was tilted $25^{\circ}$ in antiTrendelenberg to allow easier blood drainage.

Patients were continuously non-invasively monitored for electrocardiogram, MAP and heart rate $[H R]$, before induction of anesthesia to determine baseline measures and every 5 -min till end of surgery to assure maintenance of blood pressure at the adjusted level. Throughout surgery, operative field bleeding and subsequently its visibility was graded as follows: no bleeding [0], slight bleeding not necessitating suction [1], slight bleeding that sometimes needed to be sucked [2], low bleeding, but blood has to be sucked to allow field visibility [3], blood has to be often sucked and operative field is visible only right after suction [4] and high bleeding that requires constant suction otherwise surgery is hardly possible or impossible at all [25].

\section{Study Outcomes}

Primary outcome Efficacy of esmolol-induced hypotension to minimize intraoperative [IO] bleeding to an extent that allows satisfactory completion of surgery

Secondary outcomes include

1. IO blood loss was calculated as the sum of the amount of blood collected in the suction and the calculated net weight of gauze swabs.

2. Operative field visibility score

3. Operative time determined since start of surgical procedure till its end or postponing.

4. PO hemoglobin concentration as a reflection of effect of blood loss

5. Surgeon' satisfaction by operative field visibility graded as satisfactory, good or 
unsatisfactory.

Statistical analysis: Obtained data were presented as mean $\pm S D$, numbers and percentages. Results were analyzed using paired ttest, One-way ANOVA Test and Chi-square test [ $\mathrm{X}^{2}$ test]. Possible relationships were investigated using Pearson linear regression analysis. Statistical analysis was conducted using the IBM SPSS [Version 23, 2015] for Windows statistical package. $P$ value $<0.05$ was considered statistically significant.

\section{RESULTS}

Eighty-five CRS were eligible for evaluation; 13 were excluded for not fulfilling inclusion criteria and 72 patients were divided into two groups [Fig. 1]. There was non-significant [ $p>0.05]$ differences between patients of both groups as regards enrolment data [Table $1 \&$ figure 1]. Intraoperative hemodynamic changes showed significant variance in all patients compared to their baseline measures. Esmolol bolus given before induction of anesthesia significantly attenuated pressor reflexes to tracheal intubation more than induction by remifentanil. Intraoperatively, patients received esmolol developed significantly lower $H R$ and MAP measures compared to patients received remifentanil. At 10-min after infusion stoppage, patients of group B still had significantly lower HR and MAP, while at 20-min after infusion stoppage, the difference was non-significant [Table 2].

The beneficial effect of hypotensive anesthesia, irrespective of methodology, was manifested by surgical visibility scoring, where no bleeding was reported in 12 [16.7\%] patients, slight bleeding not necessitating suction in 40 patients [55.5\%], slight bleeding that sometimes required to be evacuated in 17 patients [23.6\%] and only 2 patients [4.2\%] showed low bleeding that required evacuation to allow field visibility. Patients of group $B$ showed better visibility scores [mean score of $1.1 \pm 0.8$ ] than patients of group $A$ [mean score of $1.2 \pm 0.7]$ with non-significant difference in favor of group B. However, esmolol hypotensive anesthesia did better than remifentanil hypotensive anesthesia as manifested by the significantly lower amount of intraoperative bleeding and shorter operative time [Table 3]. Median value of percentage of decreased MAP was significantly $[p=0.0005]$ higher with esmolol [25.77, IQR: 22.5-29.5] than with remifentanil [22.16, IQR: 19-24.1]. Median percentage of decreased MAP, in studied patients of both groups, showed negative significant correlation with both operative time $[r=-0.375$, $p=0.001]$ and $I O$ blood loss [ $r=-0.366, p=0.002]$ and a positive significant correlation $[r=0.396, p=0.001]$ between 10 blood loss and time. Such correlations were also manifest for both types of hypotensive anesthesia, but more pronounced with esmolol hypotensive anesthesia [Table 4].

Regarding surgeons' satisfaction scoring by hypotensive anesthesia, surgeons found it was satisfactory in 37 patients, good in 31 patients and unsatisfactory in only 4 patients with non-significant difference between both types of hypotensive anesthesia [Fig. 2].

Table [1]: Patients' enrollment data

\begin{tabular}{|l|c|c|c|}
\hline \multicolumn{1}{|c|}{ Data } & $\begin{array}{c}\text { Group A } \\
{[\mathrm{H}-\mathrm{TIVA} ; \mathrm{n}=36]}\end{array}$ & $\begin{array}{c}\text { Group B } \\
\text { [EHA; } \mathrm{n}=36]\end{array}$ & Pvalue \\
\hline Age [years] & $40.4 \pm 8.6$ & $39.2 \pm 7.4$ & 0.519 \\
\hline Gender; M: $\mathrm{F}$ & $26: 10$ & 29.7 & 0.405 \\
\hline Body mass index [kg/m²] & $29.9 \pm 2.1$ & $29.3 \pm 2.4$ & 0.266 \\
\hline ASA grade; $1:$ : II & $28: 8$ & $27: 9$ & 0.781 \\
\hline Endoscopic score & $6.5 \pm 1.2$ & $6.8 \pm 1.4$ & 0.331 \\
\hline CT score & $6 \pm 1.6$ & $6.4 \pm 2$ & 0.358 \\
\hline
\end{tabular}

Data are presented as mean $\pm S D$, numbers \& ratios; ASA: American Society of Anesthesiologists grading system 


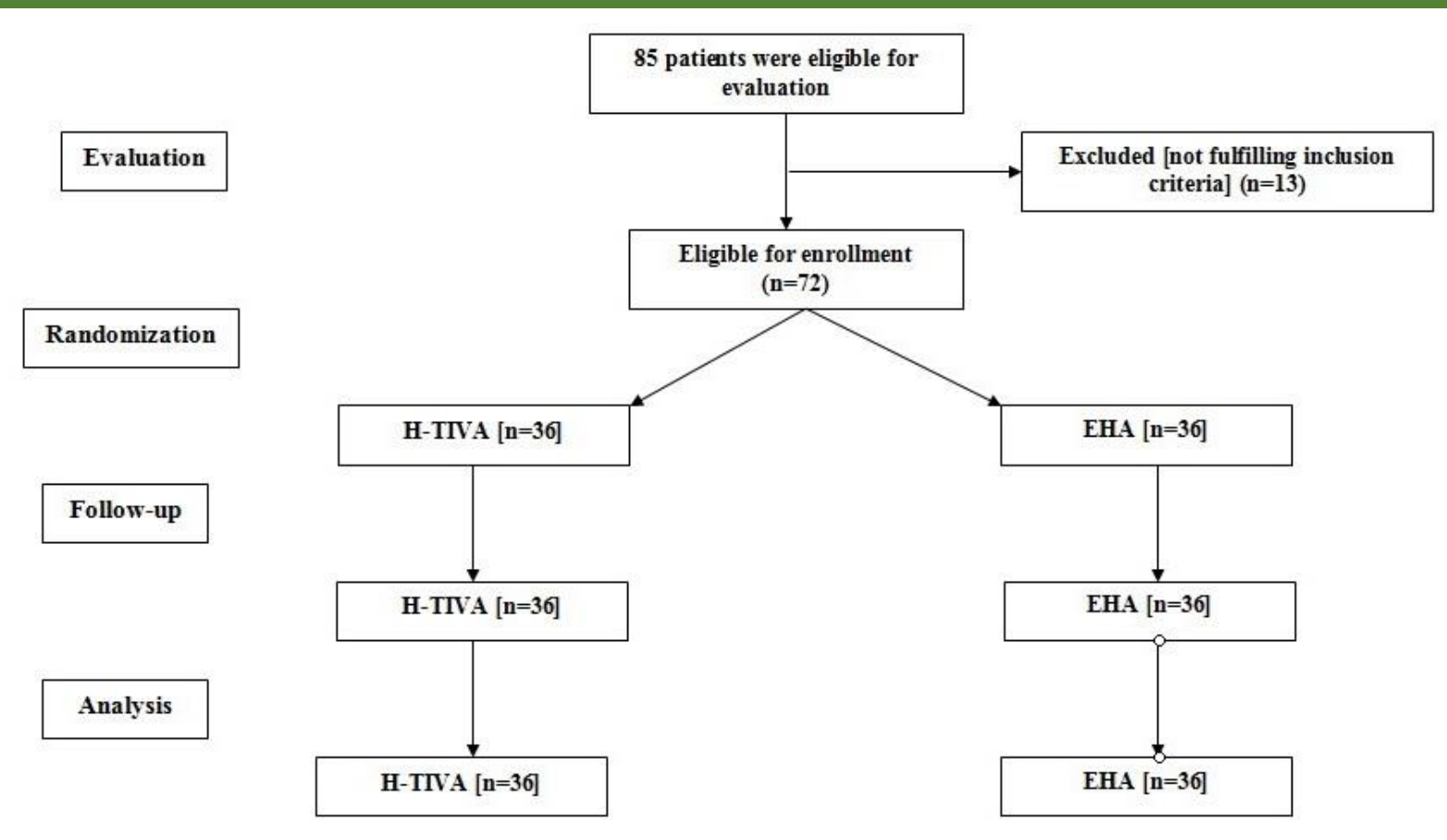

Figure 1: Consort Flow sheet

Table [2]: Hemodynamic data of patients of both groups

\begin{tabular}{|c|c|c|c|c|}
\hline Parameter & Time & $\begin{array}{c}\text { Group A } \\
\text { [H-TIVA; } n=36]\end{array}$ & $\begin{array}{c}\text { Group B } \\
{[E H A ; n=36]}\end{array}$ & $P$ value \\
\hline \multirow[t]{7}{*}{ HR [beat/min] } & Baseline & $82.9 \pm 3.8$ & $80.8 \pm 5.8$ & 0.067 \\
\hline & At intubation & $76.2 \pm 4.7$ & $72.3 \pm 7$ & 0.007 \\
\hline & $15-\min 10$ & $72.5 \pm 7.4$ & $64.5 \pm 8$ & 0.001 \\
\hline & $30-\min 10$ & $71.1 \pm 8.5$ & $63.3 \pm 7.4$ & 0.001 \\
\hline & $45-\min 10$ & $73.3 \pm 7.9$ & $64.9 \pm 8.7$ & 0.001 \\
\hline & 10-min after end of surgery & $76.9 \pm 6.4$ & $71.8 \pm 7.3$ & 0.002 \\
\hline & 20-min after end of surgery & $80.2 \pm 5.7$ & $77.2 \pm 7.9$ & 0.102 \\
\hline \multirow[t]{7}{*}{ MAP [mmHg] } & Baseline & $88.9 \pm 3$ & $89.3 \pm 3.1$ & 0.536 \\
\hline & At intubation & $74.3 \pm 4.8$ & $70.8 \pm 3.2$ & 0.001 \\
\hline & 15-min IO & $68.3 \pm 4.5$ & $66.4 \pm 3.8$ & 0.047 \\
\hline & $30-\min 10$ & $68.5 \pm 4.7$ & $64.9 \pm 4.1$ & 0.001 \\
\hline & $45-\min 10$ & $68.3 \pm 5.4$ & $63.7 \pm 4.6$ & 0.001 \\
\hline & 10-min after end of surgery & $82 \pm 3.7$ & $78.5 \pm 4$ & 0.001 \\
\hline & 20-min after end of surgery & $84.6 \pm 3.3$ & $83 \pm 4.2$ & 0.078 \\
\hline
\end{tabular}

Data are presented as mean $\pm S D$, numbers \& ratios; HR: Heart rate; MAP: Mean arterial pressure; $p>0.05$ indicates non-significant difference between groups; $p<0.05$ indicates significant difference between groups

Table [3]: Operative data of patients of both groups

\begin{tabular}{|c|c|c|c|c|}
\hline & & $\begin{array}{c}\text { Group A } \\
\text { [H-TIVA; } n=36]\end{array}$ & $\begin{array}{c}\text { Group B } \\
{[E H A ; n=36]}\end{array}$ & $P$ value \\
\hline \multirow[t]{5}{*}{ Surgical field visibility score } & 0 & $4[11.1 \%]$ & $8[22.2 \%]$ & \multirow{4}{*}{0.547} \\
\hline & 1 & $22[61.1 \%]$ & $18[50 \%]$ & \\
\hline & 2 & $8[22.2 \%]$ & $9[25 \%]$ & \\
\hline & 3 & $2[5.6 \%]$ & $1[2.8 \%]$ & \\
\hline & Mean $[ \pm S D]$ & $1.2 \pm 0.7$ & $1.1 \pm 0.8$ & 0.432 \\
\hline \multicolumn{2}{|c|}{ Amount of bleeding [ml] } & $139.5 \pm 17.3$ & $130.6 \pm 19.6$ & 0.045 \\
\hline \multicolumn{2}{|c|}{ Operative time [min] } & $59 \pm 9.3$ & $53.6 \pm 11.5$ & 0.033 \\
\hline
\end{tabular}

Data are presented as mean $\pm S D$, numbers \& ratios; ASA: American Society of Anesthesiologists grading system 
Ahmed et al.

Table [4]: Correlations between median percentage of decreased MAP, 10 blood loss and operative time in both groups

\begin{tabular}{|l|l|c|c|c|c|}
\hline \multirow{2}{*}{ Group } & \multicolumn{2}{c|}{ Median \% of decreased MAP } & \multicolumn{2}{c|}{ Operative time } \\
\cline { 3 - 6 } & IO blood loss & & $P$ & ${ }^{\prime \prime}$ & $P$ \\
\hline \multirow{2}{*}{$\begin{array}{l}\text { Group A } \\
\text { [H-TIVA; } n=36]\end{array}$} & Operative time & -0.258 & 0.129 & 0.461 & 0.005 \\
\hline \multirow{2}{*}{$\begin{array}{l}\text { Group B } \\
\text { [EHA; } n=36]\end{array}$} & IO blood loss & -0.344 & 0.040 & & \\
\cline { 2 - 6 } & Operative time & -0.341 & 0.042 & 0.314 & 0.062 \\
\hline Total & IO blood loss & -0.364 & 0.029 & & \\
\cline { 2 - 6 } & Operative time & -0.375 & 0.001 & 0.396 & 0.001 \\
\hline
\end{tabular}

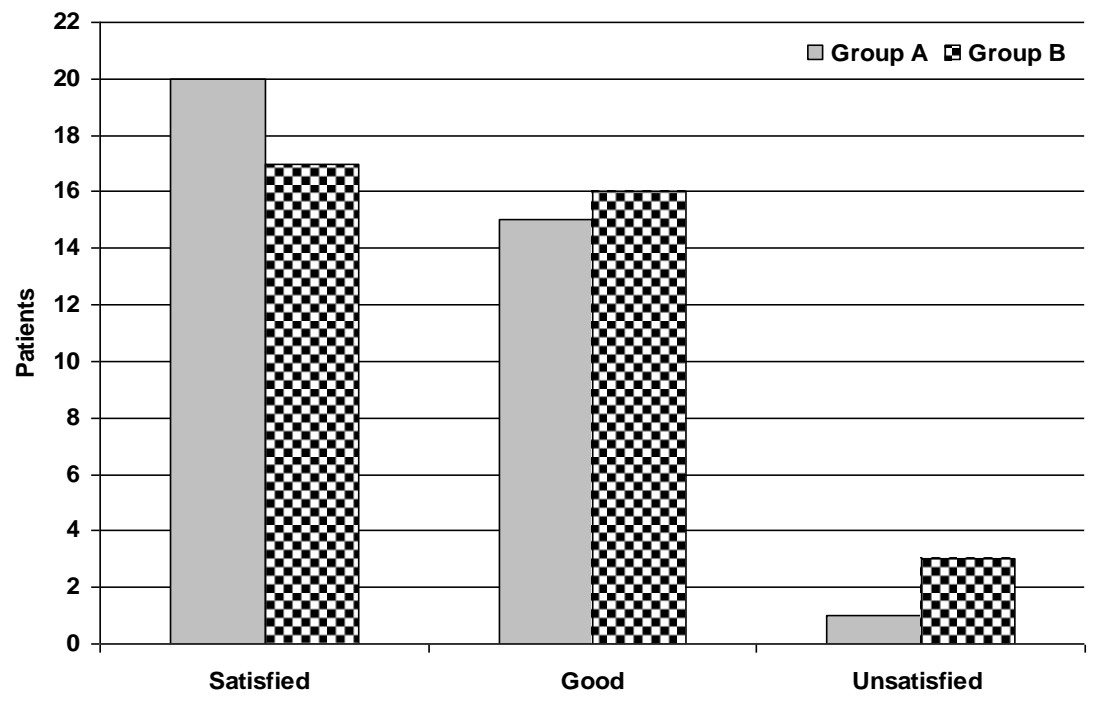

Fig. (2): Patients' distribution according to surgeons' satisfaction by hypotensive anesthesia

\section{DISCUSSION}

Hypotensive anesthesia $[\mathrm{HA}]$ using either $\mathrm{H}$ TIVA or EHA minimized IO blood loss down to no to slight bleeding in $16.7 \%$ and $55.5 \%$ of studied patients, respectively, so allowed sparing of suction use in $72.2 \%$ of surgeries. Moreover, HA-induced effect on field bleeding allowed improved field visibility during FESS to satisfactory-to-good levels in $51.4 \%$ and $43.1 \%$ of surgeries, respectively. These data indicated that FESS under HA is safe to patients and satisfactory to surgeons and thus improved surgical outcome with subsequent improvement of $\mathrm{PO}$ clinical and radiological scoring. These findings coincided with previous studies evaluated HA during FESS using magnesium sulfate versus lidocaine [13], clonidine[12, 26-28], dexmedetomedine ${ }^{[28,29]}$ and labetalol versus nitroglycerin [30].

Regarding primary outcome, EHA did better than H-TIVA; firstly, esmolol induced more hypotensive effect down to a level that was significantly lower than with remifentanil $[\mathrm{RHA}]$ but not out of the targeted level [MAP $=60-70 \mathrm{mmHg}$ ]. Moreover, EHA provided better field visibility through significantly lower amount of 10 bleeding, so allowed significant reduction of operative time than with RHA.

In line with the efficacy of esmolol for improving surgical field visibility, Guney et al. [31] reported that esmolol provided hemodynamic stability and good surgical field visibility and should be considered as an alternative to nitroglycerine during nasal surgery. Also, Ibraheim et al. [32] documented that esmolol and dexmedetomidine as adjuvant to anesthetic regimen, provided an effective and well-tolerated method for reduction of blood loss during scoliosis surgery, but dexmedetomidine induced prolonged extubation and recovery times. Thereafter, Besir et al. [33] found breast reduction surgery performed under EHA with propofol and remifentanil 
anesthesia reduced surgical duration and blood loss with improved surgical visibility than under sevofluraneand remifentanil.

Concerning FESS, Srivastava et al.[34] in comparative study between nitroglycerin and esmolol for controlled hypotension during FESS reported that both drugs improved visibility of surgical field by reducing capillary bleeding, but esmolol offered better operative conditions with only minimal reduction in MAP, no reflex tachycardia and less 10 hemorrhage. Thereafter, Jangra et al. [9], in placebo-controlled study found quality of surgical field was better with esmolol and magnesium sulfate, but duration of surgery was significantly less with esmolol than magnesium sulfate and placebo. Recently, in 2019, Lavere et al. [35] found both esmolol and labetalol reduced rate of IO blood loss, properly controlled MAP and HR, and improved surgical visibility during FESS with non-significant differences

Esmolol bolus injection before induction of anesthesia allowed priming of patient's pressor reflexes to induction and intubation as manifested by the significantly lower HR and MAP during intubation in patients received esmolol than patients who received remifentanil for induction during $\mathrm{HA}$. In support of this finding, Sharma et al. [36], in placebo-controlled study, reported that both dexmedetomidine and esmolol suppressed hemodynamic responses to intubation when compared to placebo. Also, Verma et al. [19] and Bhattacharjee et al.[37] in placebo-controlled study, found both esmolol and diltiazem ${ }^{[19]}$ or dexmedetomidine ${ }^{[37]}$ infusions, provided stable 10 hemodynamics and protected against stress response triggered by pneumoperitoneum during laparoscopic surgery, but esmolol induced significantly lower HR and blood pressures than in diltiazem at the creation of pneumoperitoneum [19]. In another comparative study, Prajwal Patel et al.[38] found both esmolol and labetalol attenuated hemodynamic response, but if patient has raised blood pressure, esmolol is a good option in blunting the response.

Interestingly, MAP estimated at 10-min after completion of surgery and stoppage of esmolol infusion was still significantly lower compared to that measures after stoppage of remifentanil infusion, but the difference became non-significant at 20-min after stoppage of infusions. This time lag between stoppage of infusion and return of MAP to level near preoperative level allowed surgical field exploration and safe extubation. These finding go in hand with Tuzcu et al. [39] who compared the effect of esmolol and remifentanil priming before induction of anesthesia and found both drugs blunted the pressor reflexes but HR values at 10 minutes after intubation were significantly decreased with esmolol than with remifentanil. Similarly, Verma et al. ${ }^{[19]}$ and Prajwal Patel et al. [38] found esmolol was more efficient than diltiazem ${ }^{[19]}$ and labetalol [38] at and immediately after extubation.

Conclusion: Hypotensive anesthesia is safe and appropriate modality for FESS and improves surgical and clinical outcome. Both esmolol and remifentanil provided satisfactory results. Esmolol is superior to remifentanil for control of induction, intubation and extubation pressor reflexes. Moreover, esmolol allowed significant reduction of IO blood loss and operative time.

\section{Conflict of Interest}

Authors declare that, there was no conflicts of interest.

\section{REFERENCES}

1. Ghogomu N, Kern R. Chronic rhinosinusitis: the rationale for current treatments. Expert Rev Clin Immunol. 2017; 13[3]:259-270. [Doi: 10.1080/ 1744666X.2016.1220833].

2. Kuhar HN, Ganti A, Eggerstedt $M$, Mahdavinia M, Gattuso P, Ghai R, Batra PS, Tajudeen BA. The impact of race and insurance status on baseline histopathology profile in patients with chronic rhinosinusitis. Int Forum Allergy Rhinol. 2019;9[6]:665673.[ Doi: 10.1002/alr.22295].

3. Kim JY, Ko I, Kim MS, Yu MS, Cho BJ, Kim DK: Association of Chronic Rhinosinusitis With Depression and Anxiety in a Nationwide Insurance Population. JAMA Otolaryngol Head Neck Surg. 2019; 145[4]:313-319. [Doi: 10.1001/jamaoto. 2018.4103].

4. Mattos JL, Rudmik L, Schlosser RJ, Smith TL, Mace JC, Alt J, Soler ZM. Symptom importance, patient expectations, and satisfaction in chronic rhinosinusitis. Int Forum Allergy Rhinol. 2019; 9[6]:593-600. [Doi: 10.1002/ alr.22309].

5. Di Mauro R, Lucci F, Martino F, Silvi MB, Gidaro E, Di Lorenzo S, et al. The role of intraoperative stroke volume variation on bleeding during functional endoscopic sinus surgery. Minerva Anestesiol. 2018; 84[11]:1246-1253. [Doi: 10.23736/S0375-9393.18.12401-1].

6. Huang Z, Hwang P, Sun Y, Zhou B. Steroid-eluting sinus stents for improving symptoms in chronic rhinosinusitis patients undergoing functional endoscopic sinus surgery. Cochrane Database Syst 
Rev. 2015; [6]:CD010436. [Doi: 10.1002/14651858. CD010436.pub2].

7. Aroor R, Sunu Ali Z, Gangadhara Somayaji KS. Do Nasal Surgeries Affect Mucociliary Clearance? Indian J Otolaryngol Head Neck Surg. 2017; 69[1]:24-28. [Doi: 10.1007/s12070-016-1016-y]

8. Cipriani 0 , Vellone V Arangio P, Della Rocca $F$. Sinus Disventilation and Atrophy of the Upper Maxilla: A Combined Surgical Approach Is Possible? J Craniofac Surg. 2017; 28[1]:e1-e3. [10.4103/0970-9185.173400].

9. Jangra K, Malhotra SK, Gupta A, Arora S: Comparison of quality of the surgical field after controlled hypotension using esmolol and magnesium sulfate during endoscopic sinus surgery. J Anaesthesiol Clin Pharmacol. 2016; 32[3]:325-8. [Doi: 10.4103/0970-9185.173400].

10. Boonmak P, Boonmak S, Laopaiboon M: Deliberate hypotension with propofol under anesthesia for functional endoscopic sinus surgery [FESS]. Cochrane Database Syst Rev. 2016; 10: CD006623. [DOI: 10.1002/14651858. CD006623.pub3].

11. Bajwa SJ, Kaur J, Kulshrestha A, Haldar R, Sethi $\mathbf{R}$, Singh A. Nitroglycerine, esmolol and dexmedetomidine for induced hypotension during functional endoscopic sinus surgery: A comparative evaluation. J Anaesthesiol Clin Pharmacol. 2016; 32[2]:192-7. [Doi: 10.4103/0970-9185.173325].

12. Jiwanmall M, Joselyn AS, Kandasamy S. Intravenous clonidine as a part of balanced anesthesia for controlled hypotension in functional endoscopic sinus surgery: A randomized controlled trial. Indian J Anaesth. 2017; 61[5]:418-423. [DOI:10.4103/ija.IJA_58_17].

13. Hamed MA. Comparative Study between Magnesium Sulfate and Lidocaine for Controlled Hypotension during Functional Endoscopic Sinus Surgery: A Randomized Controlled Study. Anesth Essays Res. 2018; 12[3]:715718. [DOI: 10.4103/ aer.AER_103_18]

14. Yuan X, Liu T, Hu C, Shen X. Comparison of surgical field visibility during propofol or desflurane anesthesia for middle ear microsurgery. BMC Anesthesiol. 2019; 19[1]:85. [Doi: 10.1186/s12871-019-0759-x].

15. Vahabi S, Rafieian Y, Abbas Zadeh A. The Effects of Intraoperative Esmolol Infusion on the Postoperative Pain and Hemodynamic Stability after Rhinoplasty. J Invest Surg. 2018; 31[2]:82-88. [Doi: 10.1080/08941939. 2016.1278288].

16. Trekova NA, Aksel'rod BA, Tolstova IA, Guleshov VA, Poplavskiî IV, Gus'kov DA. Efficiency and controllability of esmolol [breviblock]-induced adrenergic blockade during the heart and aorta surgery. Anesteziol Reanimatol. 2012; [2]:8-13. [PMID: 22834280].

17. Bensky KP, Donahue-Spencer L, Hertz GE, Anderson $M T$, James $R$. The dose-related effects of bolus esmolol on heart rate and blood pressure following laryngoscopy and intubation. AANA J. 2000; 68[5]:437-42. [PMID: 11759128].

18. Fujiwara K, Miasuda R, Takeda S. [Causative factors of esmolol-induced reduction in arterial blood pressure differ in accordance with its doses]. Masui. 2011; 60[3]:353-60. [PMID: 21485106].

19. Verma A, Srivastava D, Paul M, Chatterjee A, Chandra A. Effect of Esmolol and Diltiazem Infusions on Hemodynamic Response to Pneumoperitoneum on Laparoscopic Simple Nephrectomy: A Randomized Controlled Trial. Anesth Essays Res. 2018; 12[1]:85-91. [Doi: 10.4103/aer.AER_203_17].

20. Wiest DB, Haney JS. Clinical pharmacokinetics and therapeutic efficacy of esmolol. Clin Pharmacokinet. 2012; 51[6]:347-56. [DOI: 10.2165/11631590-00000000000000].

21. Garnock-Jones KP. Esmolol: a review of its use in the short-term treatment of tachyarrhythmias and the shortterm control of tachycardia and hypertension. Drugs. 2012; 72[1]:109-32. [DOI: 10.2165/11208210-00000000000000].

22. Report of the Rhinosinusitis Task Force Committee Meeting. Alexandria, Virginia, August 17, 1996. Otolaryngol Head Neck Surg. 1997 Sep. 117[3 Pt 2]:S1-68. [PMID:9380416].

23. Lund VJ, Kennedy DW. Quantification for staging sinusitis. International Conference on Sinus Disease: Terminology, Staging, Therapy. Ann Otol Rhinol Laryngol Suppl, 1995; 167: 17-21. [PMID: 7574265].

24. Lund VJ, Mackay IS. Staging in rhinosinusitis. Rhinology 1993; 31:183-4. PMID: 8140385

25. Fromme GA, MacKenzie RA, Gould AB, Lund BA, Offord KP. Controlled hypotension for orthognatic surgery. Anesth Analg. 1986; 65: 683-6. [PMID:3706806].

26. Cardesín A, Pontes C, Rosell R, Escamilla Y, Marco J, Escobar MJ, Bernal-Sprekelsen M. Hypotensive anesthesia and bleeding during endoscopic sinus surgery: an observational study. Eur Arch Otorhinolaryngol. 2014; 271[6]:1505-11. [Doi: 10.1007/ s00405-013-2700-0].

27. Cardesin A, Pontes C, Rosell R, Escamilla Y, Marco J, Escobar MJ, Bernal-Sprekelsen M. A randomised double blind clinical trial to compare surgical field bleeding during endoscopic sinus surgery with clonidine-based or remifentanil-based hypotensive anaesthesia. Rhinology. 2015; 53[2]:107-15. [Doi: 10.4193/ Rhin14.185].

28. Das A, Mukherje A, Chhaule S, Chattopadhyay S, Halder PS, Mitra T, Basunia SR, Mandal SK. Induced hypotension in ambulatory functional endoscopic sinus surgery: A comparison between dexmedetomidine and clonidine as premedication. A prospective, double-blind, and randomized study. Saudi J Anaesth. 2016; 10[1]:7480. [Doi: 10.4103/ 1658-354X.169480].

29. Shams T, El Bahnasawe NS, Abu-Samra M, El-Masry R. Induced hypotension for functional endoscopic sinus surgery: A comparative study of dexmedetomidine versus esmolol. Saudi J Anaesth. 2013; 7[2]:175-80. [Doi: 10.4103/1658-354X.114073]

30. El-Shmaa NS, Ezz HAA, Younes A. The efficacy of Labetalol versus Nitroglycerin for induction of controlled hypotension during sinus endoscopic surgery. A 
prospective, double-blind and randomized study. J Clin Anesth. 2017; 39:154-158. [Doi: 10.1016/ j.jclinane. 2017.03.003].

31. Guney A, Kaya FN, Yavascaoglu B, Gurbet A, Selmi $\mathbf{N H}$, Kaya S, Kutlay $\mathbf{0}$. Comparison of esmolol to nitroglycerine in controlling hypotension during nasal surgery. Eurasian J Med. 2012; 44[2]:99-105. [Doi: 10.5152/eajm.2012.23].

32. Ibraheim OA, Abdulmonem A, Baaj J, Zahrani TA, Arlet V. Esmolol versus dexmedetomidine in scoliosis surgery: study on intraoperative blood loss and hemodynamic changes. Middle East J Anaesthesiol. 2013; 22[1]:27-33. [PMID: 23833847].

33. Besir A, Cekic B, Kutanis D, Akdogan A, Livaoglu M. Comparison of surgical conditions in 2 different anesthesia techniques of esmolol-induced controlled hypotension in breast reduction surgery. Medicine [Baltimore]. 2017; 96[10]:e6254. [Doi: 10.1097/ MD.0000000000006254].

34. Srivastava U, Dupargude AB, Kumar D, Joshi K, Gupta A. Controlled hypotension for functional endoscopic sinus surgery: comparison of esmolol and nitroglycerine. Indian J Otolaryngol Head Neck Surg. 2013; 65[Suppl 2]:440-4. [Doi: 10.1007/ s12070-013-0655-5].

35. Lavere PF, Rana NA, Kinsky MP, Funston JS, Mohamed SS, Chaaban MR. Blood Loss and Visibility with Esmolol vs Labetalol in Endoscopic Sinus Surgery: A Randomized Clinical Trial. Clin Med Insights Ear Nose Throat. 2019; 12:1179550619847992. [Doi: 10.1177/ 1179550619847992. eCollection 2019].
36. Sharma S, Suthar OP, Tak ML, Thanvi A, Paliwal $\mathbf{N}$, Karnawat R. Comparison of Esmolol and Dexmedetomidine for Suppression of Hemodynamic Response to Laryngoscopy and Endotracheal Intubation in Adult Patients Undergoing Elective General Surgery: A Prospective, Randomized Controlled Double-blinded Study. Anesth Essays Res. 2018; 12[1]:262-266. [Doi: 10.4103/aer.AER_226_17].

37. Bhattacharjee DP, Saha S, Paul S, Roychowdhary S, Mondal S, Paul S. A comparative study of esmolol and dexmedetomidine on hemodynamic responses to carbon dioxide pneumo-peritoneum during laparoscopic surgery. Anesth Essays Res. 2016; 10[3]:580-584. [DOI:10.4103/0259-1162.183564].

38. Prajwal Patel HS, Shashank MR, Shivaramu BT. Attenuation of Hemodynamic Response to Tracheal Extubation: A Comparative Study between Esmolol and Labetalol. Anesth Essays Res. 2018; 12[1]:180-185. [Doi: 10.4103/aer.AER_130_17].

39. Tuzcu K, Tuzcu EA, Karcioglu M, Davarci I, Coskun M, Ilhan O, Daglıoglu MC, Turhanoglu S. The effects of remifentanil and esmolol on increase in intraocular pressure due to laryngoscopy and tracheal intubation: a double-blind, randomized clinical trial. J Glaucoma. 2015; 24[5]:372-6. [Doi: 10.1097/IJG.0b013e31829f9bfe]. 